\title{
Compression therapies for chronic venous leg ulcers: interventions and adherence
}

This article was published in the following Dove Press journal:

Chronic Wound Care Management and Research

9 January 2015

Number of times this article has been viewed

\author{
Christopher A Latz' \\ Kellie R Brown ${ }^{2}$ \\ Ruth L Bush' \\ 'Texas A\&M Health Science Center \\ College of Medicine, Bryan, TX, \\ USA; ${ }^{2}$ Medical College of Wisconsin, \\ Milwaukee, WI, USA
}

\begin{abstract}
Compression therapy has been the mainstay for the treatment of lower extremity edema, venous insufficiency, and particularly, venous ulcerative disease. Though modern surgical treatments exist, none are completely effective without good compressive options to allow for decreased swelling and better oxygenation of damaged tissues. This review article will describe the pathophysiology and presentation of lower extremity venous ulcerations, as well as current options for compression therapy. The benefits, along with the major pitfall of nonadherence, will also be discussed.
\end{abstract}

Keywords: venous disease, chronic venous insufficiency, venous ulceration

\section{Introduction}

Venous leg ulcers have afflicted humans throughout our existence. King Henry VIII of medieval England reportedly suffered from recurrent venous leg ulcers, with intermittent sepsis theorized to hamper his judgment on state issues. ${ }^{1}$ Compression therapy itself is quite ancient, with reported use by Hippocrates dating back to the 4th century BC. ${ }^{2}$ Interestingly, compression is still considered the gold standard of treatment for venous leg ulcers today. ${ }^{3}$

Chronic venous leg ulcers are a common, and often difficult to treat, condition encountered in modern medical practice across a broad array of specialties. Proper care for these patients requires the cooperation of a team of clinicians and health care providers, from physicians to wound care specialists. ${ }^{4}$ Approximately $1.5-3.0$ per 1,000 adults have active leg ulcers, $80 \%$ of which develop secondary to underlying venous disease. ${ }^{1,5}$ The direct cost of treatment for venous leg ulcers in the US is currently estimated to be between US\$10,000-US\$12,000 per patient. Additionally, significant indirect costs are associated with lost work productivity and other related expenses. ${ }^{1}$ These unfortunate patients suffer from a lower quality of life due to decreased mobility, pain, and subsequent loss of income..$^{6,7}$

Various treatment modalities currently exist for the treatment of chronic venous ulceration, such as compression bandaging, other compressive therapy, vascular surgery for arterial occlusive disease including lower extremity bypass or endovascular procedures, skin replacement and grafting, and various biophysical interventions, as well as endovascular surgical interventions in cases of deep vein stenosis, occlusion, or external compression. ${ }^{4}$ Several trials have shown that healing rates of venous ulcers are $<50 \%$ at 12 weeks after the start of therapy. Other trials have shown that this rate can be significantly improved with the use of adequate and consistent compression materials. ${ }^{8,9}$
Texas A\&M Health Science Center, MS I359 8447 State Highway 47, HPEB 3064, Bryan, TX, USA

Tel +l 979436024 I

Fax + I 9794360092

Email rbush@medicine.tamhsc.edu 
Iliac vein recanalization with stenting has been shown to be very efficacious in the healing of chronic venous ulcerations. ${ }^{10,11}$ Raju et al ${ }^{10,11}$ have shown in multiple studies that the long-term patency and clinical outcomes are excellent. The need for open surgery to correct reflux or obstruction has been drastically reduced; however, such procedures can still be carried out later in the event of stent occlusion or failure to relieve symptoms.

The options for venous ulcer treatment are conservative therapy with compression, leg elevation, and ambulation; while other therapy options include surgery by means of great saphenous vein ligation and stripping, or less invasive alternatives such as endovascular ablation or foam sclerotherapy. Perforator vein interruption is also an option to promote ulcer healing when indicated. ${ }^{12}$ Additionally, investigational cell-based topical treatments are currently being studied in the treatment of venous leg ulcers. ${ }^{13}$ The general consensus is that both compression and surgery are equally effective in promoting ulcer healing and improving patient quality of life; however, surgery has been shown to have a lower rate of recurrence. ${ }^{12}$

A core component of the current management of venous ulcerations is compression therapy. ${ }^{4}$ It has been shown that venous ulcers heal faster when compression therapy is administered. ${ }^{3}$ In an overview of guidelines from both the Association of Advanced Wound Care (AAWC) in 2012 and the Wound Healing Society (WHS) in 2006 (with an update in 2012), consensus is that multiple sustained high compression elastic bandages should be used instead of inelastic compression or single component compression systems, as this method has been shown to be more effective. ${ }^{4}$ If this is unable to be accomplished, however, compression of any form has been shown to be better than none. ${ }^{3}$ After a wound has healed, compression stockings should be used lifelong to reduce ulcer recurrence. ${ }^{4}$ In this review, compression therapy options and their role in the treatment of venous ulcers will be discussed.

\section{Overview of venous disease}

\section{Pathophysiology}

The venous system is comprised of high capacitance vessels, designed to accommodate large volume changes, such as those that occur with exercise. Pathology, including venous valvular insufficiency and calf muscle pump dysfunction, leads to chronic blood pooling within the lower extremities with a subsequent increase in venous pressure. This increase in venous pressure is responsible for the signs and symptoms that are so commonly associated with chronic venous disease. ${ }^{14-16}$ Persons who have had a prior deep vein thrombosis (DVT) are particularly prone to deep venous insufficiency and post-thrombotic syndrome, which may ultimately lead to ulceration. ${ }^{17,18}$

Calf muscle pump deficiency, in particular, appears to have a significant association with venous ulceration. ${ }^{19}$ Additionally, nutritional deficiency of wound-healing nutrients may play a significant role in the propagation of chronic venous ulcers; particularly protein, vitamins $\mathrm{C}$ and $\mathrm{A}$, and zinc. ${ }^{20}$ Obesity also plays a role in the development of chronic venous ulcers, as obesity is associated with decreased mobility and subsequent venous stasis. ${ }^{4}$

\section{Etiology of chronic venous ulcers}

The true pathophysiological mechanism behind ulcer formation from venous hypertension is not entirely clear. There is some literature supporting the pathological changes that occur locally with venous hypertension. These include fibrin cuff formation around the microvasculature, which serves as a barrier to oxygen diffusion; impaired gas exchange; local ischemia and epidermal necrosis; white cell entrapment; and inhibition of growth factors, all as proposed mechanisms behind the skin breakdown and poor healing. ${ }^{21-24}$

A proposed mechanism for the characteristic skin changes associated with venous disease, including ulceration, involves extravasation of blood particles into tissues secondary to increased pressure and capillary filtration, leading to hemosiderin deposition and subsequent hyperpigmentation. Neutrophil accumulation and fibrin breakdown trigger inflammation and increased microthrombi, ultimately leading to impaired local oxygen delivery. ${ }^{5}$

Ulcers trapped in the inflammatory phase are unlikely to heal. This may be caused by an imbalance between matrix metalloproteinases (MMPs) and elastase and the MMP inhibitors. Certain dressings can trap MMPs in the form of oxidized regenerated collagen and cellulose, and may help to promote wound healing. ${ }^{5}$

\section{Clinical presentation}

Symptoms of chronic venous insufficiency (CVI) are extremely variable and often vague. Symptom patterns commonly include dull pain, leg heaviness, fatigue or restlessness, and swelling that worsen throughout the day. Pruritus, burning sensations, cramping, skin tension and thickening, and visible varicosities are also common complaints. Unfortunately, CVI is a progressive disease and usually worsens in severity over time. Severe disease may lead to dermatitis, soft tissue edema, hyperpigmentation, 
lipodermatosclerosis, ulceration, skin erosion, or hemorrhage. Pain associated with CVI is often exacerbated by pregnancy and variation in the menstrual cycle. ${ }^{25}$

Signs of CVI are also quite variable. The first sign is typically ankle and calf edema. Early signs also include telangiectasias and visible reticular veins, palpable intradermal veins, and visible larger varicosities. Longstanding disease manifests with more skin changes, such as brawny induration, stasis dermatitis, hyperpigmentation, and finally, with skin ulceration in the most severe form. ${ }^{26}$

\section{Diagnosis}

Venous disease is characterized by the Clinical Etiologic Anatomic Pathophysiologic (CEAP) System. The grading system goes from $\mathrm{C}_{1}-\mathrm{C}_{6} \cdot \mathrm{C}_{1}$ disease is characterized by visible telangiectasias and/or visible intradermal (reticular) veins. Varicose veins comprise $\mathrm{C}_{2}$ or $\mathrm{C}_{3}$ disease depending on whether or not they are symptomatic (with $\mathrm{C}_{2}$ being asymptomatic and $\mathrm{C}_{3}$ being symptomatic); however, the distinction between $\mathrm{C}_{2}$ and $\mathrm{C}_{3}$ disease is rarely made clinically. $\mathrm{C}_{4}$ disease is composed of those who have trophic skin changes such as pigmentation, eczema, lipodermatosclerosis, and atrophie blanche (hypopigmentation due to cutaneous infarction). $\mathrm{C}_{5}$ is designated when a healed venous ulcer is in place, while $\mathrm{C}_{6}$ disease consists of an active venous ulcer. ${ }^{1,26-29}$

Diagnosis of venous disease begins with a thorough history and physical examination. Particular attention should be given toward eliciting any history of DVT or prior surgical intervention. Additionally, if present, all lower extremity incisions must be inspected to determine if stab avulsion phlebectomies or saphenous vein stripping has been previously performed. ${ }^{30}$

When venous disease is suspected, a focused venous Duplex ultrasound should be performed to examine both the deep and superficial venous system. This will confirm the diagnosis and stage of the extent of disease. ${ }^{30}$ Additionally, patients with $\mathrm{C} 5$ or C6 disease are more likely to have perforator vein insufficiency, and imaging needs to extend to the area directly beneath the ulcer beds. ${ }^{31-33}$

\section{Review of current compression therapies}

The force of gravity causes venous ulceration to occur in the most dependent areas of the lower extremities. It has recently been proven that the mechanism behind mechanical compression stockings is related to a decrease in the transmural pressure within the vein wall by increasing the perivenous tissue pressure. ${ }^{34}$ Compression may also provide additional benefit by reducing the vein remodeling known to occur in CVI patients. ${ }^{35}$ Compression therapy, therefore, counteracts the force of gravity by applying perivenous tissue pressure. ${ }^{9}$ This external pressure provides force to move fluid from the interstitial space back into the intravascular space, as well as prevent reflux. ${ }^{36,37}$ External pressure also increases calf-pumping function and induces a valvular mechanism to increase venous ejection fraction, prevent reflux, and decrease ambulatory venous hypertension. ${ }^{38,39}$ Compression therapy requires lifelong maintenance to prevent ulcer recurrence. ${ }^{5}$

The parameters responsible for clinical efficiency of compression therapies are the stiffness (pressure increase caused by stretching of the compression material), and the interface pressure exerted on the leg. ${ }^{9}$ In order to effectively modify standing venous pressure, the external compression pressure applied should exceed $60 \mathrm{mmHg}$, which is the pressure required to compress veins effectively while in the dorsiflexed position. ${ }^{40}$ Patients treated with the highest degrees of compression have the lowest reported recurrence rates. ${ }^{41,42}$ Optimizing compression systems over the years has proven to be a challenging endeavor. This is due to different combinations of materials often being poorly described in trials, use of confusing terminology, and failure to report the proper pressures and the physical properties of various compression products. ${ }^{1}$ One must also ascertain the status of the patient's arterial system in the lower extremities to avoid compression in the face of peripheral arterial disease.

\section{Available compression therapies}

For compression therapy of venous leg ulcers, there are currently five materials that are presently utilized. These include: compression bandages, compression stockings, self-adjustable fabric hook and loop fastener (eg, 'Velcro ${ }^{\circledR}$ ') devices, intermittent pneumatic compression pumps, and hybrid devices. ${ }^{9}$ Each of these treatment modalities will be discussed (Table 1).

\section{Compression bandages}

Bandages are categorized by their performance into retention, support, or compression type bandages. ${ }^{3}$ When it comes to venous insufficiency treatment, most interest lies in compression bandages. Class 3 bandages are compression-type bandages, and are classified on the level of compression at the ankle when the bandage is applied in a simple spiral. Class $3 \mathrm{a}$ provides light compression (14-17 $\mathrm{mmHg}$ ), class $3 \mathrm{~b}$ provides moderate compression (18-24 $\mathrm{mmHg}$ ), class 3c provides high compression $(25-35 \mathrm{mmHg})$, and class $3 \mathrm{~d}$ provides extra high compression (up to $60 \mathrm{mmHg}$ ). ${ }^{43,44}$ 
Table I Comparison of various compression materials

\begin{tabular}{|c|c|c|c|c|c|c|}
\hline \multicolumn{2}{|c|}{ Type (I-4) } & \multirow{2}{*}{$\begin{array}{l}\text { Example } \\
\text { Zinc paste (Unna) }\end{array}$} & \multirow{2}{*}{$\begin{array}{l}\text { Application } \\
\text { Trained staff, may } \\
\text { stay for some days }\end{array}$} & \multirow{2}{*}{$\begin{array}{l}\text { Advantages } \\
\text { High working pressure, } \\
\text { well-tolerated during rest }\end{array}$} & \multirow{2}{*}{$\begin{array}{l}\text { Disadvantages } \\
\text { Messy }\end{array}$} & \multirow{2}{*}{$\begin{array}{l}\text { Stiffness } \\
\text { Very high }\end{array}$} \\
\hline la) & Inelastic & & & & & \\
\hline lb) & Short stretch wrap & $\begin{array}{l}\text { Double } \\
\text { Comprilan }^{\odot}\end{array}$ & $\begin{array}{l}\text { Trained staff, may } \\
\text { stay for some days }\end{array}$ & $\begin{array}{l}\text { High working pressure, } \\
\text { well-tolerated during rest }\end{array}$ & Slipping & High \\
\hline Ic) & $\begin{array}{l}\text { Multicomponent - } \\
\text { short stretch }\end{array}$ & Coban2 $^{\odot}$ & $\begin{array}{l}\text { Trained staff, may } \\
\text { stay for some days }\end{array}$ & $\begin{array}{l}\text { High working pressure, } \\
\text { well-tolerated during } \\
\text { rest, less slippage }\end{array}$ & Not reusable & High \\
\hline Id) & $\begin{array}{l}\text { Long stretch wrap - } \\
\text { elastic }\end{array}$ & $\begin{array}{l}\text { Ace }^{\odot} \\
\text { Perfekta }^{\odot}\end{array}$ & $\begin{array}{l}\text { Easy application, needs to } \\
\text { be removed overnight }\end{array}$ & $\begin{array}{l}\text { Self-application, } \\
\text { restricted reusability }\end{array}$ & $\begin{array}{l}\text { Low working pressure, } \\
\text { not tolerated when } \\
\text { applied with high pressure }\end{array}$ & Low \\
\hline le) & $\begin{array}{l}\text { Multicomponent } \\
\text { bandages }\end{array}$ & $\begin{array}{l}\text { Profore }^{\odot} \text { (elastic } \\
\text { components); } \\
\text { Urgo KTwo }{ }^{\odot} \text { (inelastic = } \\
\text { elastic component) }\end{array}$ & $\begin{array}{l}\text { Trained staff, may stay } \\
\text { for some days }\end{array}$ & $\begin{array}{l}\text { High working pressure, } \\
\text { well-tolerated during rest }\end{array}$ & $\begin{array}{l}\text { Not reusable, bulky, } \\
\text { and warm }\end{array}$ & High \\
\hline $2 a)$ & $\begin{array}{l}\text { Compression } \\
\text { stocking elastic }\end{array}$ & $\begin{array}{l}\text { Variety of products in } \\
\text { different compression } \\
\text { classes }\end{array}$ & Self-application & $\begin{array}{l}\text { Patient can have } \\
\text { showers, daily skin care, } \\
\text { self-management }\end{array}$ & $\begin{array}{l}\text { Low working pressure, } \\
\text { difficult to put on }\end{array}$ & Low \\
\hline $2 b)$ & ) Ulcer kits & Double stocking & $\begin{array}{l}\text { Basal layer stays overnight } \\
\text { and keeps ulcer dressing } \\
\text { in place, second stocking } \\
\text { during daytime }\end{array}$ & $\begin{array}{l}\text { Patient can have } \\
\text { showers, daily skin } \\
\text { care, self-management }\end{array}$ & Difficult to put on & Medium \\
\hline 3) & Velcro devices & CircAid $^{\odot}$ & $\begin{array}{l}\text { Self-application, } \\
\text { self-adjustable }\end{array}$ & $\begin{array}{l}\text { Patient can have } \\
\text { showers, daily skin } \\
\text { care, self-management }\end{array}$ & Not appealing & $\begin{array}{l}\text { Medium- } \\
\text { high }\end{array}$ \\
\hline 4) & Extremity pump & $\begin{array}{l}\text { Variety of products in } \\
\text { different versions }\end{array}$ & $\begin{array}{l}\text { Self-application, } \\
\text { self-adjustable }\end{array}$ & $\begin{array}{l}\text { Patient can have } \\
\text { showers, daily skin } \\
\text { care, self-management }\end{array}$ & $\begin{array}{l}\text { Works when patient is } \\
\text { resting for limited time } \\
\text { Adjunctive use }\end{array}$ & Variable \\
\hline 5) & $\begin{array}{l}\text { 'Hybrid pumps' } \\
\text { ('adaptive compression } \\
\text { therapy') }\end{array}$ & $\begin{array}{l}\text { Actitouch }^{\odot} \\
\text { Combines sustained with } \\
\text { intermittent pressure }\end{array}$ & $\begin{array}{l}\text { Self-application, } \\
\text { pressure-sustained } \\
\text { mode is maintained }\end{array}$ & $\begin{array}{l}\text { Patient can have } \\
\text { showers, daily skin } \\
\text { care, self-management }\end{array}$ & Not appealing & Variable \\
\hline
\end{tabular}

Note: Reproduced with permission of Gale SS, Lurie F, Treadwell T, et al. DOMINATE Wounds. Wounds. 2014:26(I): I-I2.9.72

This classification system has recently been under scrutiny, and a more complex classification has been proposed. An expert consensus group recommends that a distinction be made between layers and components of various compression bandages ${ }^{40}$ Additionally, the notion of a 'static stiffness index' (SSI) has been proposed, as properties of 'elastic' bandages may become more 'inelastic' due to the friction forces between different components. The new proposal is for SSIs $>10 \mathrm{mmHg}$ when a patient moves from supine to standing to indicate inelasticity, and an increase of $<10 \mathrm{mmHg}$ to indicate elasticity. ${ }^{40}$

The available compression bandages can be broken down into the following groups: inelastic bandages (eg, traditional Unna boot; Figure 1), short stretch bandages (eg, Double Comprilan $^{\circledR}$; BSN Medical, Hull, UK), multiple component short stretch bandages (eg, Coban 2тM; 3M Co, St Paul, MN, USA), long stretch bandages (eg, Ace ${ }^{\mathrm{TM}} ; 3 \mathrm{M} \mathrm{Co}$ ), and multiple component (multi-layer) bandages (eg, Profore ${ }^{\mathrm{TM}}$; Smith and Nephew, London, UK or KTwo ${ }^{\circledR}$; Urgo Ltd, Loughborough, UK). They all tend to have a high working pressure, except for the long stretch elastic wraps. ${ }^{2,5,9,45}$
Inelastic bandages have the highest stiffness of all compression materials. ${ }^{39,46}$ They are well-tolerated during periods of rest and do not require daily application, but tend to be messy and require application by trained staff. ${ }^{2,42}$ Short stretch wrap systems have a high stiffness, also tend to be well-tolerated during periods of rest, do not

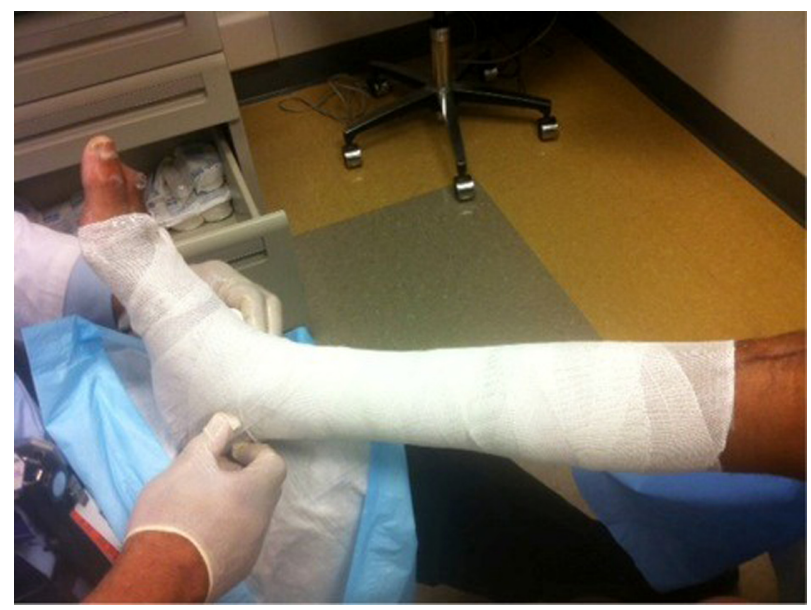

Figure I Traditional Unna's Boot with multiple layers for compression. 
require daily application, and are washable and therefore reusable, but may slip and require application by trained staff. ${ }^{41}$ Multicomponent short stretch systems have a high stiffness, do not require daily application, and are welltolerated during periods of rest, but are not reusable and require application by trained staff. ${ }^{41}$ Long stretch elastic wrap can be applied by the patient or an assistant, but have a low stiffness, are not well-tolerated when applied with a high pressure, and must be removed nightly. ${ }^{2}$ Multiple component bandages have a high stiffness and are welltolerated during periods of rest, but are bulky, warm, and not reusable. They require placement by trained staff, but do not require daily application. ${ }^{8}$

\section{Multiple component vs single component compression bandages}

Compression systems can secondarily be classified into single layer and multilayer, and also, into multiple versus single component. A multilayer system is one in which one bandage is applied in an overlapping manner leading to a multilayer bandage. Graduated compression stockings have a single compression layer. Multiple component systems may have multiple different materials combined into a single compression system. As a whole, it appears that multicomponent compression is more effective than single component compression systems. ${ }^{3}$

A popular multiple component system is the four-layer bandage (4LB) system (Figure 2). A 4LB has four components consisting of orthopedic wool, a crepe bandage, an elastic bandage, and an outer layer made of an elastic cohesive bandage. It is important to note that application of multiple layers both increases pressure, as well as changes the elastic properties of the final bandage due to friction forces between the surfaces of each of the bandages. The end result is a final

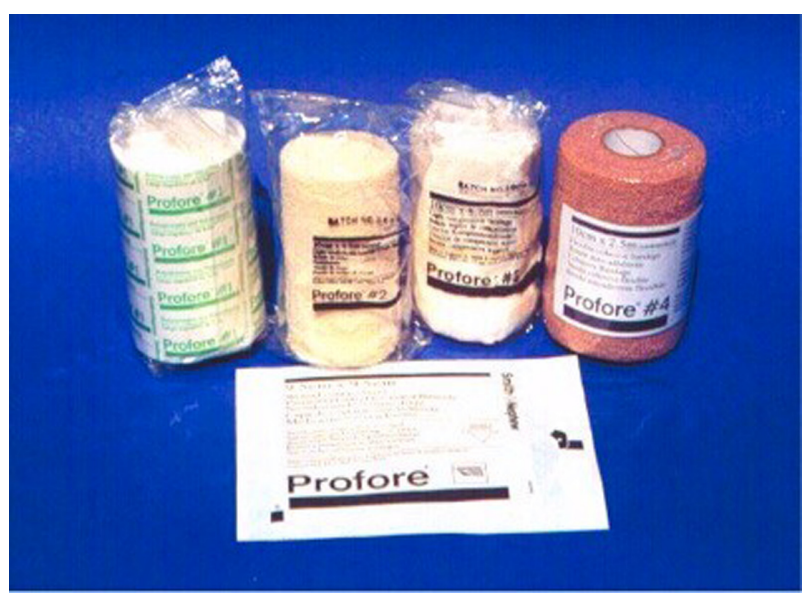

Figure 2 Components of a four-layer compression bandage system. bandage layer that is less elastic but with increased stiffness (with an SSI >10). 1,9,39 Multicomponent bandage systems also often incorporate short stretch bandages. ${ }^{1}$ These must be considered when interpreting data regarding multiple component systems.

Current moderate-quality evidence supports the use of multicomponent bandages over single component bandage systems for the treatment of venous leg ulcers. ${ }^{47}$ A recently performed meta-analysis pooled data from six trials comparing a $4 \mathrm{LB}$ to an short stretch bandage system. The results showed a $30 \%$ improvement in ulcer healing in the $4 \mathrm{LB}$ arm. ${ }^{1}$ It should be noted, however, that these results might indicate lack of proper technique when applying SSB compression systems, as studies in the Netherlands and Austria showed no significant differences between the two systems with regard to ulcer healing. ${ }^{1,3}$ 4LB systems have the additional benefit of being more cost-effective than the SSB alternative. ${ }^{3}$ No specific 4LB system is currently endorsed, as all currently marketed systems appear to perform similarly. ${ }^{41}$

\section{Compression stockings}

Compression stockings (elastic prescription hosiery) are classified in a manner similar to bandages, according to compression pressure exerted on the limbs. The pressure is also measured at the level of the ankle. Class 1 stockings provide light support (14-17 $\mathrm{mmHg}$ ), class 2 provides medium support (18-24 $\mathrm{mmHg}$ ), and class 3 provides strong support (25-35 mmHg). Class 1 stockings are used to treat varicose veins, class 2 are used for more severe varicosities and help prevent venous leg ulcers, and class 3 are used to treat severe venous hypertension and severe varicose veins, and also help to prevent new or recurrent venous leg ulcers. ${ }^{3,48}$

Compression stockings (Figure 3) currently come in two varieties - as elastic compression stockings or as ulcer kits (ie, double stockings). Compression stockings are selfapplicable, but can be difficult to put on and tend to have lower working pressure than their compression bandage counterparts. They allow for daily skin care and showers. The only difference in the ulcer kits is that they contain a basal layer that stays in place overnight to keep the ulcer dressing in place, while the second stocking is placed over it daily. ${ }^{49}$

Data pooled from four randomized controlled trials showed that high-compression stockings are associated with faster healing than SSB systems at 2-4 months. ${ }^{3}$ There was also no significant difference in complete healing between compression stockings compared to two-component and 4LB bandage systems at 3 months. Stockings have the additional 


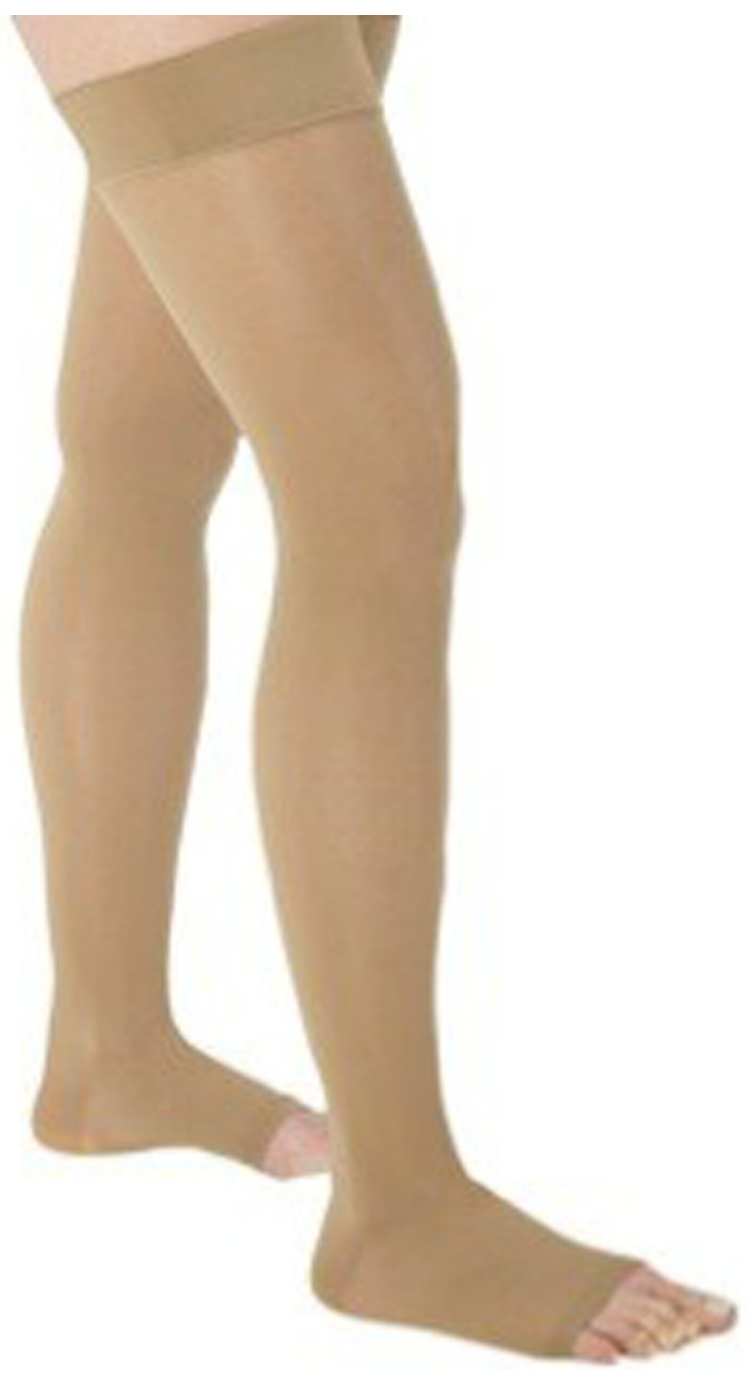

Figure 3 Classic thigh-high graduated compression hosiery.

benefit of being subjected to less operator-dependent variability than are bandages. As a whole, however, studies comparing elastic stockings to inelastic bandages should be interpreted with caution, as the bandage pressure is extremely variable, and dependent on the stretch applied to the bandage, as well as the experience of the person performing application of the bandage. This makes it difficult to accurately compare the two devices. ${ }^{39}$

\section{Velcro devices}

Fabric hook and fastener, ie, Velcro ${ }^{\mathrm{TM}}$ devices (eg, CircAid ${ }^{\circledR}$ Medical Products; MediGLobal, Miami, FL, USA), are self-applicable with patient-controlled adjustable pressure (Figure 4). They provide medium-to-high stiffness, while allowing for daily skin care and showers. They are the only inelastic compression devices currently on the market that can be self-applied by patients. They tend to not be as appealing

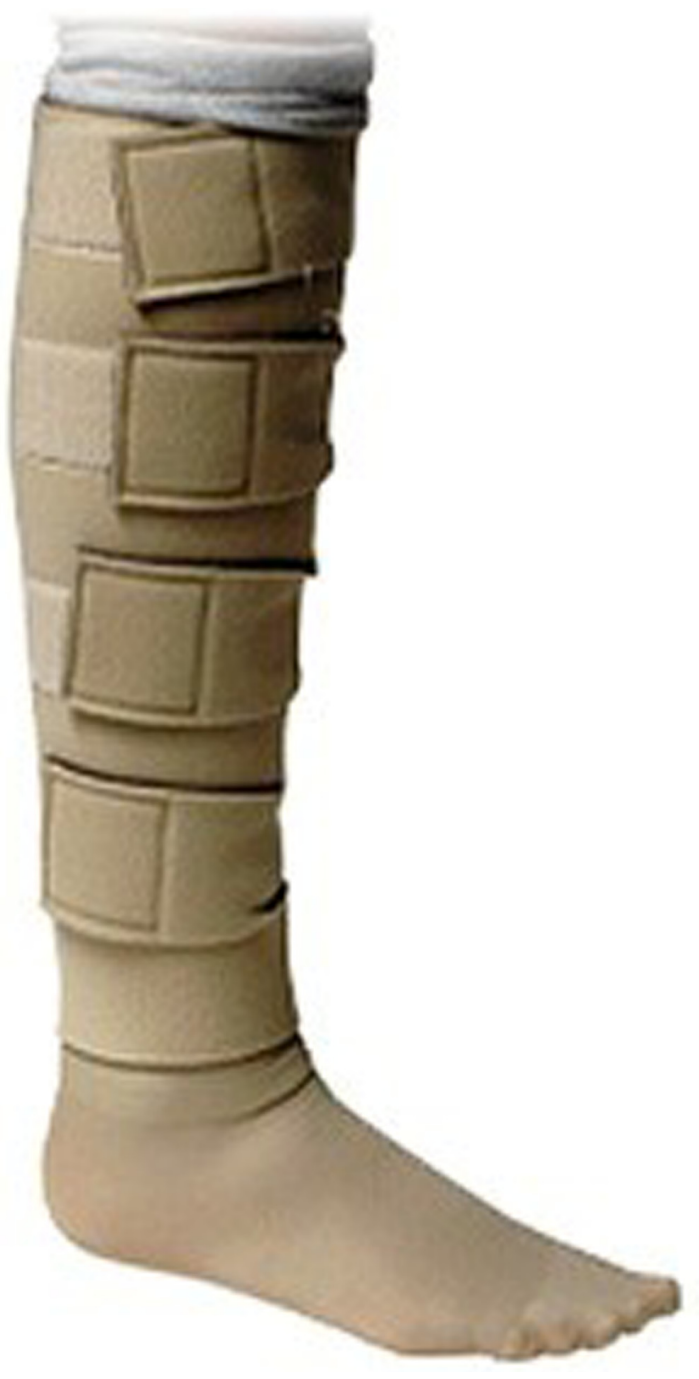

Figure 4 Compression with Velcro straps for self-adjustment to allow patient to control pressure.

to patients as alternative compression therapies, however, due to their bulkiness and restriction of mobility. ${ }^{1,40}$

\section{Intermittent pneumatic compression therapy}

Intermittent pneumatic compression pumps, often used for DVT prophylaxis, have been shown to assist in the healing of chronic ulceration. ${ }^{50}$ They can be used with a full compression system, or as an alternative to those patients who are unable to wear a full compression system. ${ }^{51}$ However, it is recommended only when other compression therapies cannot be used (ie, patients with reduced mobility), are not available, or have failed after prolonged compression therapy. ${ }^{1}$ These devices produce a waveform motion of pressure on the leg. In terms of ulcer healing, however, meta-analysis results have been inconclusive. ${ }^{9}$ The major advantage is that these devices work while the patient is resting. ${ }^{50,52}$ 


\section{Hybrid devices}

Hybrid devices (eg, CompreFit BK; Spectrum Healthcare, Phoenixville, PA, USA) combine sustained compression with intermittent compression therapy, which is utilized during periods of patient rest. ${ }^{9}$ They allow for self-application and daily skin care and showers with variable stiffness. Hybrid devices tend to be less appealing to patients as compression alternatives. ${ }^{5}$

\section{Elastic versus inelastic compression}

Compression can be classified into elastic and inelastic categories. Elastic bandages have maximal extensibility $>100 \%$, and contain elastomeric fibers, while inelastic bandages have a maximal extensibility of $<100 \%{ }^{5}$ An intelligent compression system will exert strong pressure in the standing position and low pressure in the supine position. This difference is referred to as the SSI. The SSI is measured at the $\mathrm{B} 1$ point of the gastrocnemius muscle (the transition between the muscular and tendinous portion of the medial gastrocnemius) as the difference between the resting pressure in the lying position and standing pressure. Another important indicator of bandage stiffness is the pulse pressure during muscular activity, or the walking pressure amplitude (WPA), which is another indicator of bandage stiffness. ${ }^{12}$ Pressure produced by compression systems depends on several factors, including the limb size, activity level of the patient, skill of application, and application technique. ${ }^{5}$

Elastic compression systems exert a small pressure difference between resting pressure, standing pressure, and pressure during exercise. The SSI is typically $<10 \mathrm{mmHg}$, and the WPA tends to be very low. Elastic bandages should be applied at $50 \%$ of the total extensibility to avoid pain during application. ${ }^{12}$ Elastic bandages are effective in edema reduction, but are less effective than inelastic bandages in improving venous pumping function and subsequent hemodynamics. ${ }^{1}$ In order to achieve a pressure of $>60 \mathrm{mmHg}$ in the upright position, elastic bandages have to be applied at extremely high resting pressures, which would be intolerable for patients.

A recent Cochrane review concluded that the most effective compression systems are multicomponent systems that contain an elastic bandage. ${ }^{3}$ The studies that have drawn these conclusions have been called into question, however, due to proposed flaws in their methodology. ${ }^{39}$ It is currently accepted that elastic stockings exerting the highest pressure tolerable should be used to prevent ulcer recurrence after healing. ${ }^{42}$

Inelastic bandages are non-stretchable textiles. An example is the Unna boot. ${ }^{9}$ Inelastic bandages are well-tolerated, even when applied with a strong initial pressure, due to the immediate reduction in edema and subsequent decrease in leg volume. Inelastic systems also exert a higher pressure during standing, with an SSI $>10 \mathrm{mmHg}$, and peak pressure of $>70 \mathrm{mmHg}$ during exercise, bringing inelastic compression systems close to fitting the definition of an ideal compression system. ${ }^{12}$ Studies have concluded that inelastic compression material is more effective than elastic bandages at reducing deep venous reflux and superficial venous insufficiency, as inelastic bandages produce much higher standing pressures than due elastic material. ${ }^{39}$ Inelastic materials are also more effective at improving venous pumping function than elastic materials. Additionally, inelastic material is able to exert a positive effect on hemodynamics at pressures as low as $20 \mathrm{mmHg}$, which may be beneficial in the use of mixed arteriovenous ulcers (see next section). The positive effect on ejection fraction exerted by inelastic material was maintained as long as 7 days after application despite a decrease in observed pressure..$^{53}$ The lower resting pressure afforded by inelastic bandages makes them more tolerable and less likely to cause pain in patients with arterial disease relative to elastic compression systems. ${ }^{36,46,54}$ Previous studies claiming superiority of elastic material relative to inelastic material may have been performed without adequate measurement of the pressure of the compression devices, and the elastic dressings in said studies may actually have had properties closer to inelastic dressings. ${ }^{12}$ Therefore, it is recommended that larger, randomized trials without methodological errors be conducted before any conclusion is made over which material is superior in the compression therapy of venous leg ulcers. ${ }^{39}$

\section{Treatment of arteriovenous ulcers}

Up to $30 \%$ of lower extremity ulcers have an arterial component. Treatment of mixed leg ulcers (those in which arterial disease is also contributing to ulcer formation) present unique challenges with regard to treatment. Compression will improve venous hemodynamics, but can further impair arterial inflow. In a recent study, Mosti et al ${ }^{36}$ utilized laser Doppler flowmetry (LDF) and transcutaneous oxygen measurements in patients with combined atherosclerotic disease and venous ulcers before and after application of high strength compression to determine whether or not compression would further impair arterial perfusion. In this limited study of 25 patients, inelastic compression bandages were applied with compression pressures ranging from $20-50 \mathrm{mmHg}$ in attempts to identify a cutoff point where arterial perfusion decreased. Blood flow actually increased 
close to the ulcer (as measured under bandages) applying all pressure ranges, but the amount of increase was greater with bandages applying 20-40 mmHg of pressure. At the toe level, a significant decrease in perfusion was noted with bandages that applied $>41 \mathrm{mmHg}$ of pressure. The authors concluded that for patients with an ankle-brachial index $(\mathrm{ABI})>0.5$ and an ankle pressure $>60 \mathrm{mmHg}$, bandages applying up to $40 \mathrm{mmHg}$ did not reduce arterial perfusion, and actually improved LDF at the local ulcer level. ${ }^{36,39}$

Patients with an ABI of 0.8-1.2, indicative of an adequate lower extremity vascular supply, are good candidates for high compression therapy. Those with an ABI between $0.5-0.8$ should use reduced strength compression so as to avoid distal gangrene and limb loss. For those with an $\mathrm{ABI}<0.5$, compression therapy is contraindicated until a comprehensive vascular assessment deems otherwise. ${ }^{36,55}$

\section{Ulcer recurrence}

As previously mentioned, the potential for ulcer recurrence without maintenance compression therapy has been reported to be as high as $67 \%{ }^{56,57}$ When compliant with compression therapy, the reported recurrence rate is $28 \%$. When compression therapy is combined with superficial venous surgery, the recurrence rate drops to $12 \% .{ }^{58}$ As previously mentioned, to prevent ulcer recurrence, elastic stockings exerting the highest pressure tolerable are recommended. ${ }^{42}$

\section{Supplementation with pharmacotherapy}

Supplementation of compression therapy with pentoxifylline (Trental ${ }^{\circledR}$; Sanofi SA, Paris, France) has improved healing of venous ulcers, producing an estimated $21 \%$ increase in overall healing, with the most commonly encountered side effect being gastrointestinal disturbance. ${ }^{59}$ Micronized purified flavonoid fraction has also been shown to be beneficial in ulcer healing in combination with compression therapy. However, neither of these pharmacotherapy adjuncts are often used clinically. ${ }^{1}$

\section{Compliance with compression therapy}

Compliance remains the Achilles heel of compressive therapy. Reviews have shown that the benefits of compression therapy diminish according to the level of nonadherence. ${ }^{60}$ As previously mentioned, compression therapy requires lifelong adherence. Compliance with long-term therapy is cited at 37\%-67\%. Reasons commonly stated for noncompliance include heat accumulation, inconvenience, high cost, and pain. ${ }^{61}$ Adherence is also influenced by patient beliefs as to how worthwhile the therapy will be for their condition. ${ }^{59}$ Younger patients often refuse compression therapy, while older patients may experience difficulty in applying compressive devices. ${ }^{62}$ Venous leg ulcer recurrence rate is estimated at $26 \%$ at 1 year following complete ulcer closure. ${ }^{63}$ Therefore, it is important to determine which interventions are most likely to promote adherence to compression therapy and appropriately counsel and educate the patient.

Current therapy for venous leg ulcers usually includes a combination of compression, possible surgery, physical therapy, local wound care, drug therapies, and leg ulcer care at community clinics. ${ }^{64}$ Patients often receive either home nursing care or attend wound clinics for regular wound care. An interesting model for therapy currently being studied is the use of community-based clinics designed to increase patient compliance. Unfortunately, systematic reviews are currently unable to determine if these community-based clinics increase patient compliance over standard home or outpatient clinic care. ${ }^{64}$ In two current studies, so-called 'Leg Clubs' are a model designed to provide social support in a supportive, informative environment. ${ }^{64}$ A similar model, known as 'Lively Legs', which evaluates patient lifestyle and beliefs in a community clinic setting with the aim to promote patient adherence, ${ }^{65}$ has been evaluated in single-centered randomized controlled trials. On review of the Leg Clubs study, it was concluded that healing rates and quality of life may not improve any more than home-based visits for people with venous leg ulcers; and on review of the Lively Legs study, healing rates, recurrence, and adherence to therapy were not increased more than regular attendance to an outpatient wound clinic. ${ }^{64}$ There is currently limited evidence to truly assess the benefits of communitybased nursing models of care, and more trials are needed before quality evidence can be obtained. ${ }^{64}$

\section{Quality of life issues}

Not surprisingly, patients with chronic venous leg ulcers suffer from a lower health-related quality of life (HRQOL) because of their disease. Patients report suffering from pain, sleep disturbance, and increased social isolation because of their disease. In a systematic review conducted on quality of life studies for patients with venous ulcers, the most frequent symptom reported is pain, which was commonly described as a constant reminder of their disease. ${ }^{7}$ Pain was reportedly exacerbated during dressing changes and analgesia was often inadequate. ${ }^{66,67}$

Patients also suffer restriction in mobility secondary to ulcer-related pain and leakage of exudate. ${ }^{68}$ In the study by 
Walshe, many patients felt that inadequate methods were employed to manage exudate and associated odor, leading to increased social isolation and increased self-consciousness. ${ }^{68}$ Another study echoed these results, finding many patients reporting an inability to maintain hygiene, which contributed to social isolation. ${ }^{69}$ In one quality of life study, it was shown that swelling was a good predictor of impaired mobility, financial trouble, decreased working capacity, and negative effects on emotional health. On the other hand, ulcer size was not shown to affect any of these quality of life factors. This study indicated that control of swelling might have a large impact on patient quality of life. ${ }^{6}$ In another study, investigators determined that the significant emotional distress associated with chronic venous leg ulcers often goes undetected by care providers. ${ }^{70}$ Patient energy levels were shown to improve with ulcer treatment, with the greatest improvement in energy level noted in those whose ulcer had completely healed. ${ }^{71}$ Sleep disturbance is also a common complaint, which is attributable to ulcer-related pain. ${ }^{68}$

In summary, it is recommended that to improve the HRQOL of these patients, care providers should individualize strategies to manage wound exudate and subsequent odor, provide comprehensive care pathways for ulcer management, foster a collaborative clinician-patient relationship, and provide proper patient education materials. ${ }^{7,71}$ Patients may benefit from particular attention to reducing their leg swelling. ${ }^{6}$

\section{Conclusion}

Compression therapy remains the gold standard for treatment of venous leg ulcerations. It is clearly superior with regard to ulcer healing rates compared with no compression.

Current evidence suggests that multiple component bandages (ie, two-component and 4LB systems) perform better than single component bandages, and compression hosiery appears to perform as well as two-component and $4 \mathrm{LB}$ systems, with the additional benefit of being less operator dependent. However, there is still the need for more high quality research to determine which exact combination of material provides the best overall compression. There is also controversy in the literature over whether inelastic or elastic compression stockings are superior, and even debate over the definition of elastic and inelastic materials themselves. It seems clear that elastic stockings exerting the highest pressure tolerable should be used to prevent ulcer recurrence.

Just as important as finding the proper compression system, is promoting patient compliance with lifelong compression therapy, given the high rate of ulcer recurrence following successful closure. An improved interdisciplinary approach and enhanced patient education are likely key components. There needs to be more investigation into ways to improve patient compliance, as this will lead to decreased morbidity associated with venous disease.

\section{Disclosure}

The authors report no conflicts of interest in this work.

\section{References}

1. O'Donnell TF Jr, Passman MA, Marston WA, et al; Society for Vascular Surgery; American Venous Forum. Management of venous leg ulcers: clinical practice guidelines of the Society for Vascular Surgery ${ }^{\circledR}$ and the American Venous Forum. J Vasc Surg. 2014;60(Suppl 2): 3S-59S.

2. Turner-Boutle M, Fletcher A, Sheldon T, Cullum N. Compression therapy for venous ulcers: a systematic review. Nurs Times. 1997;93(39): $52-53$.

3. O’Meara S, Cullum N, Nelson EA, Dumville JC. Compression for venous leg ulcers. Cochrane Database Syst Rev. 2012;11:CD000265.

4. White-Chu EF, Conner-Kerr TA. Overview of guidelines for the prevention and treatment of venous leg ulcers: a US perspective. J Multidiscip Healthc. 2014;7:111-117.

5. Woo KY, Alavi A, Evans R, Despatis M, Allen J. New advances in compression therapy for venous leg ulcers. Surg Technol Int. 2013;23: 61-68.

6. Phillips T, Stanton B, Provan A, Lew R. A study of the impact of leg ulcers on quality of life: financial, social, and psychologic implications. J Am Acad Dermatol. 1994;31(1):49-53.

7. Green J, Jester R. Health-related quality of life and chronic venous leg ulceration: part 1. Br J Community Nurs. 2009;14(12):S12, S14, S16-S17.

8. Partsch H. Compression therapy of venous ulcers. Curr Problems Dermatol. 1999;27:130-140.

9. Partsch H. Compression for the management of venous leg ulcers: which material do we have? Phlebology. 2014;29(1 Suppl):140-145.

10. Raju S, Neglén P. Stents for chronic venous insufficiency: why, where, how and when - a review. J Miss State Med Assoc. 2008;49(7):199-205.

11. Raju S, Owen S Jr, Neglen P. The clinical impact of iliac venous stents in the management of chronic venous insufficiency. J Vasc Surg. 2002;35(1):8-15.

12. Mosti G. Compression and venous surgery for venous leg ulcers. Clin Plast Surg. 2012;39(3):269-280.

13. Kirsner RS, Marston WA, Snyder RJ, Lee TD, Cargill DI, Slade HB. Spray-applied cell therapy with human allogeneic fibroblasts and keratinocytes for the treatment of chronic venous leg ulcers: a phase 2 , multicentre, double-blind, randomised, placebo-controlled trial. Lancet. 2012;380(9846):977-985

14. Ricotta JJ, Dalsing MC, Ouriel K, Wakefield TW, Lynch TG. Research and clinical issues in chronic venous disease. Cardiovasc Surg. 1997;5(4):343-349.

15. Tsai S, Dubovoy A, Wainess R, Upchurch GR Jr, Wakefield TW, Henke PK. Severe chronic venous insufficiency: magnitude of the problem and consequences. Ann Vasc Surg. 2005;19(5):705-711.

16. Henke P, Kistner B, Wakefield TW, Eklof B, Lurie F. Reducing venous stasis ulcers by fifty percent in 10 years: the next steps. J Vasc Surg. 2010;52(Suppl 5):37S-38S.

17. Armstrong DG. Addition of surgical correction to compression therapy reduced recurrences in chronic venous leg ulceration. ACP J Club. 2007;147(3):73.

18. Barnes GD, Gafoor S, Wakefield T, Upchurch GR Jr, Henke P, Froehlich JB. National trends in venous disease. J Vasc Surg. 2010; 51(6):1467-1473. 
19. Araki CT, Back TL, Padberg FT, et al. The significance of calf muscle pump function in venous ulceration. JVasc Surg. 1994;20(6):872-877; discussion 878-879.

20. Theilla M. Nutrition support for wound healing in the intensive care unit patient. World Rev Nutr Diet. 2013;105:179-189.

21. Jones NA, Webb PJ, Rees RI, Kakkar VV. A physiological study of elastic compression stockings in venous disorders of the leg. Br J Surg. 1980;67(8):569-572.

22. Coleridge Smith PD. From skin disorders to venous leg ulcers: pathophysiology and efficacy of Daflon $500 \mathrm{mg}$ in ulcer healing. Angiology. 2003;54 Suppl 1:S45-S50.

23. Gourdin FW, Smith JG Jr. Etiology of venous ulceration. South Med J. 1993;86(10):1142-1146.

24. Browse NL. The etiology of venous ulceration. World J Surg 1986;10(6):938-943.

25. Lohr JM, Bush RL. Venous disease in women: epidemiology, manifestations, and treatment. JVasc Surg. 2013;57(4 Suppl):37S-45S.

26. Beebe-Dimmer JL, Pfeifer JR, Engle JS, Schottenfeld D. The epidemiology of chronic venous insufficiency and varicose veins. Ann Epidemiol. 2005;15(3):175-184.

27. Deatrick KB, Wakefield TW, Henke PK. Chronic venous insufficiency: current management of varicose vein disease. Am Surg. 2010;76(2): 125-132.

28. O'Donnell TF Jr, Passman MA. Clinical practice guidelines of the Society for Vascular Surgery (SVS) and the American Venous Forum (AVF) - Management of venous leg ulcers. Introduction. J Vasc Surg. 2014;60(Suppl 2):1S-2S.

29. Myers KA. Classification and grading of chronic venous disease in the lower limbs: a consensus statement. American Venous Forum. Aust N Z J Surg. 1995;65(11):769-772.

30. Bush RL, Ramone-Maxwell C. Endovenous and surgical extirpation of lower-extremity varicose veins. Semin Vasc Surg. 2008;21(1):50-53.

31. Carr SC. Diagnosis and management of venous ulcers. Perspect Vasc Surg Endovasc Ther. 2008;20(1):82-85.

32. Marrocco CJ, Atkins MD, Bohannon WT, Warren TR, Buckley CJ, Bush RL. Endovenous ablation for the treatment of chronic venous insufficiency and venous ulcerations. World J Surg. 2010;34(10): 2299-2304.

33. Rueda CA, Bittenbinder EN, Buckley CJ, Bohannon WT, Atkins MD, Bush RL. The management of chronic venous insufficiency with ulceration: the role of minimally invasive perforator interruption. Ann Vasc Surg. 2013;27(1):89-95.

34. Rohan CP, Badel P, Lun B, Rastel D, Avril S. Biomechanical response of varicose veins to elastic compression: a numerical study. J Biomech. 2013;46(3):599-603.

35. Travers JP, Brookes CE, Evans J, et al. Assessment of wall structure and composition of varicose veins with reference to collagen, elastin and smooth muscle content. Eur J Vasc Endovasc Surg. 1996;11(2): 230-237.

36. Mosti G, Iabichella ML, Partsch H. Compression therapy in mixed ulcers increases venous output and arterial perfusion. JVasc Surg. 2012;55(1): $122-128$.

37. Flour M, Clark M, Partsch H, et al. Dogmas and controversies in compression therapy: report of an International Compression Club (ICC) meeting, Brussels, May 2011. Int Wound J. 2013;10(5):516-526.

38. Galm O, Jansen-Genzel W, von Helden J, Wienert V. Plasma human atrial natriuretic peptide under compression therapy in patients with chronic venous insufficiency with or without cardiac insufficiency. Vasa. 1996;25(1):48-53.

39. Mosti G. Compression in leg ulcer treatment: inelastic compression. Phlebology. 2014;29(1 Suppl):146-152.

40. Partsch H, Clark M, Mosti G, et al. Classification of compression bandages: practical aspects. Dermatol Surg. 2008;34(5):600-609.

41. Nelson EA. Compression therapy, dressings and topical agents for venous ulcer healing. Phlebology. 2010;25 Suppl 1:28-34.

42. Nelson EA, Bell-Syer SE. Compression for preventing recurrence of venous ulcers. Cochrane Database Syst Rev. 2012;8:CD002303.
43. Compression therapy for venous leg ulcers. Drug Ther Bull. 2000;38(4): 28-31

44. Amsler F, Willenberg T, Blättler W. In search of optimal compression therapy for venous leg ulcers: a meta-analysis of studies comparing diverse [corrected] bandages with specifically designed stockings. J Vasc Surg. 2009;50(3):668-674.

45. Mosti G. Post-treatment compression: duration and techniques. Phlebology. 2013;28 Suppl 1:21-24.

46. Mosti G, Mattaliano V, Partsch H. Inelastic compression increases venous ejection fraction more than elastic bandages in patients with superficial venous reflux. Phlebology. 2008;23(6):287-294.

47. Mauck KF, Asi N, Elraiyah TA, et al. Comparative systematic review and meta-analysis of compression modalities for the promotion of venous ulcer healing and reducing ulcer recurrence. JVasc Surg. 2014; 60(Suppl 2):71S-90S. e1-e2.

48. Palfreyman SJ, Lochiel R, Michaels JA. A systematic review of compression therapy for venous leg ulcers. Vasc Med. 1998;3(4):301-313.

49. Palfreyman SJ, Nelson EA, Lochiel R, Michaels JA. Dressings for healing venous leg ulcers. Cochrane Database Syst Rev. 2006;(3):CD001103.

50. Berliner E, Ozbilgin B, Zarin DA. A systematic review of pneumatic compression for treatment of chronic venous insufficiency and venous ulcers. J Vasc Surg. 2003;37(3):539-544.

51. Robson MC, Cooper DM, Aslam R, et al. Guidelines for the treatment of venous ulcers. Wound Repair Regen. 2006;14(6):649-662.

52. Alpagut U, Dayioglu E. Importance and advantages of intermittent external pneumatic compression therapy in venous stasis ulceration. Angiology. 2005;56(1):19-23.

53. Mosti G, Partsch H. Inelastic bandages maintain their hemodynamic effectiveness over time despite significant pressure loss. J Vasc Surg. 2010;52(4):925-931.

54. Mosti G, Mattaliano V, Partsch H. Influence of different materials in multicomponent bandages on pressure and stiffness of the final bandage. Dermatol Surg. 2008;34(5):631-639.

55. Stout N, Partsch H, Szolnoky G, et al. Chronic edema of the lower extremities: international consensus recommendations for compression therapy clinical research trials. Int Angiol. 2012;31(4):316-329.

56. Callam MJ, Harper DR, Dale JJ, Ruckley CV. Chronic ulcer of the leg: clinical history. Br Med J (Clin Res Ed). 1987;294(6584):1389-1391.

57. Gloviczki P, Gloviczki ML. Evidence on efficacy of treatments of venous ulcers and on prevention of ulcer recurrence. Perspect Vasc Surg Endovasc Ther. 2009;21(4):259-268.

58. Barwell JR, Davies CE, Deacon J, et al. Comparison of surgery and compression with compression alone in chronic venous ulceration (ESCHAR study): randomised controlled trial. Lancet. 2004;363(9424): 1854-1859.

59. Jull AB, Mitchell N, Arroll J, et al. Factors influencing concordance with compression stockings after venous leg ulcer healing. $J$ Wound Care. 2004;13(3):90-92.

60. Sackett DL, Rosenberg WM, Gray JA, Haynes RB, Richardson WS. Evidence based medicine: what it is and what it isn't. BMJ. 1996; 312(7023):71-72.

61. Labropoulos N, Wang ED, Lanier ST, Khan SU. Factors associated with poor healing and recurrence of venous ulceration. Plast Reconstr Surg. 2012;129(1):179-186.

62. Blattler W, Zimmet SE. Compression therapy in venous disease. Phlebology. 2008;23(5):203-205.

63. Reich-Schupke S, Murmann F, Altmeyer P, Stücker M. Quality of life and patients' view of compression therapy. Int Angiol. 2009;28(5):385-393.

64. Weller CD, Buchbinder R, Johnston RV. Interventions for helping people adhere to compression treatments for venous leg ulceration. Cochrane Database Syst Rev. 2013;9:CD008378.

65. Heinen M, Borm G, van der Vleuten C, Evers A, Oostendorp R, van Achterberg $\mathrm{T}$. The Lively Legs self-management programme increased physical activity and reduced wound days in leg ulcer patients: results from a randomized controlled trial. Int J Nurs Stud. 2012;49(2): $151-161$. 
66. Hollinworth H, Collier M. Nurses' views about pain and trauma at dressing changes: results of a national survey. JWound Care. 2000;9(8): 369-373.

67. Douglas V. Living with a chronic leg ulcer: an insight into patients' experiences and feelings. J Wound Care. 2001;10(9): 355-360.

68. Walshe C. Living with a venous leg ulcer: a descriptive study of patients' experiences. J Adv Nurs. 1995;22(6):1092-1100.

69. Ebbeskog B, Ekman SL. Elderly persons' experiences of living with venous leg ulcer: living in a dialectal relationship between freedom and imprisonment. Scand J Caring Sci. 2001;15(3):235-243.
70. Nelson EA, Cullum N, Jones J. Venous leg ulcers. Clin Evid. 2002;(8): 2031-2045.

71. Green J, Jester R. Health-related quality of life and chronic venous leg ulceration: part 2. Br J Community Nurs. 2010;15(3):S4-S6, S8, S10, passim.

72. Gale SS, Lurie F, Treadwell T, et al. DOMINATE Wounds. Wounds. 2014:26(1):1-12.

\section{Publish your work in this journal}

Chronic Wound Care Management and Research is an international, peer reviewed, open access, online journal publishing original research, reviews, editorials, and commentaries on the causes and management of chronic wounds and the major issues related to chronic wound management. Topics also include chronic wounds as comorbidities to other conditions, patient adherence to therapy, and the economic burden of chronic wounds. The manuscript management system is completely online and includes a very quick and fair peer review system, which is all easy to use. Visit http://www.dovepress.com/testimonials.php to read real quotes from published authors.

Submit your manuscript here: http://www.dovepress.com/chronic-wound-care-management-and-research-journal 